\title{
sciendo
}

DOI 10.2478/sbe-2019-0018

SBE no. 14(1) 2019

\section{PERFORMANCE MANAGEMENT SYSTEMS - PROPOSING AND TESTING A CONCEPTUAL MODEL}

\author{
ȘERBAN Radu-Alexandru \\ Lucian Blaga University of Sibiu, Romania \\ HERCIU Mihaela \\ Lucian Blaga University of Sibiu, Romania
}

\begin{abstract}
:
The utility of performance measurement and management system can be said to have been proven, but the problem faced by both the theoreticians and practitioners is to set the right performance indicators. Developed models are tools that managers can use to measure and manage performance, but they need to be tailored to the context. Also, the trend towards using non-financial performance indicators makes it very difficult for managers to design a performance measurement and management system because it involves the integration of qualitative and non-quantitative variables and a profound understanding of the internal and external environment of the company.
\end{abstract}

Key words: indicators, management, model, performance, system

\section{Introduction}

Even though performance management systems are very popular, several studies show consistent results from organisations that do not manage their performance well. They have to take into account the complexity of the performance-creating value link, and the approaches in conceptualising this link in performance management and implementing a long-term strategy at company level have created great difficulties and debates in this direction. Unless more attention is paid to performance-based behaviour, where managers act as a model, the performance management system is impossible to be effective. On the one hand, the implementation of the performance management system depends on the behavioural factors of employees and managers, and on how managers direct/train their employees towards the performance management system, and on the other hand the proper set of performance indicators are the measures that gives the organization a clear 
idea if it moves in the right direction and at the right speed and gives a good overview to the board of directors about the company's progress in terms of strategy.

\section{Literature review}

The association of the word "system" with performance management is due to its connotations with the notion of mechanism, according to Armstrong (2009) and it is used by several authors such as Neely et al. (2000), Magretta and Stone (2002), Davis and Albright (2004) which also include the term "measurement" in discussion, Lohman et al, (2004), Franco and Bourne (2005), Lee (2005), Olsen et al. (2007), Ferreira and Otley (2009) and Melnyk et al. (2013). Indeed, the phrase "performance management system" is generally used. The explanation is that it requires the application of some interdependent activities that are treated as a whole, and that's what a system does, Armstrong (2009) argues. Even though the authors mentioned above share a similar terminology, the approaches might vary. For eg. Magretta and Stone (2002) claim that the performance management system communicates the strategic intention and its importance to the rest of the organization in relation to what has been measured and what has not been measured, or the approach of Lohman et al. (2004) and Olsen et al. (2007) who proposed a change in the perspective of an integrated performance management system going through the "design approach" to the "coordination approach". Also, Deloitte (2013) used the integrated approach as a foundation when they came up with the "Deloitte IPM wheel". On the other hand others have been focusing on what it is measured in the performance management system, like BCG's performance management system approach, where the key performance indicators or KPI's play a crucial role in the system, and it requires both relevant and consistent performance metrics that capture the critical aspects of the business strategy.

The evolution of performance management and/or measurement systems were influenced by the approaches that were in trend at that time. At the beginning (1900-1914) the accounting perspective shaped the systems (e.g. DuPont Model), then the financial perspective came in the scene (e.g. Tableau de Bord), later on, the integrative approach combined with the previous ones were the basis for numerous frameworks developed, one that became very popular, Norton and Kaplan's Balanced Scorecard (1992). It's popularity, and large-scale use came from the idea behind The Balanced Scorecard which was to focus more on non-financial indicators, considering that at that time companies were only starting to see the potential of intangible assets. Some have criticized the Balanced Scorecard for being too simplistic and less aware of the external environment, and by others for the stakeholder issue arguing that this model ignores employees and regulators (Bourne and Bourne, 2012).

They are starting from the 'weakness' of the scorecard model, which does not include all the stakeholders, the nowadays approach that has a great influence on the performance and/or measurement systems used by companies. The focus has moved towards who benefits from performance results, and Porter and Kramer introduced the concept of "Creating Shared Value" or CSV in 2011, but what has become the mainstream today, are sustainability, ESG - Environmental, Social and Governance and circular economy. What these concepts did was a wake-up call for the private sector, 
governmental institutions, academics, general population and so on, that we need to be more concerned about how we handle the resources and how to build a future for the next generations. As a result, it has an impact on how performance management and/or measurement system is designed because of it vital to include the aspects mentioned above by developing metrics that are capable of measuring the results of implementing such a system for all the stakeholders.

\section{Performance management system - Conceptual model}

The multitude of approaches that the concept of performance has, highlights its importance for both academics and practitioners. On the one hand, for the academic environment, the challenge is to identify and synthesize the most important factors that determine a company's performance and include them into a performance management and measurement system, and for practitioners the challenge comes from adapting these systems to realities: economic, financial, social, environmental, etc.

The utility of a performance management model to best capture the concept of performance measured both financially, and non-financially will have a direct impact on the system. For this reason, we can see that systems have evolved, increased in complexity and gave a new dimension to the concept of performance.

Based on the facts presented above, and taking into consideration that in management, the objective of a systemic approach is to understand and control complex and evolutionary structures, in addition, the great contribution made by the systemic approach is that it studies the organization from a multidisciplinary point of view, integrated, both analytically and synthetically, starting from the expected strategic objectives and taking into account the multiple interdependencies between its components, we proposed a conceptual model of a performance management system, see figure 1 .

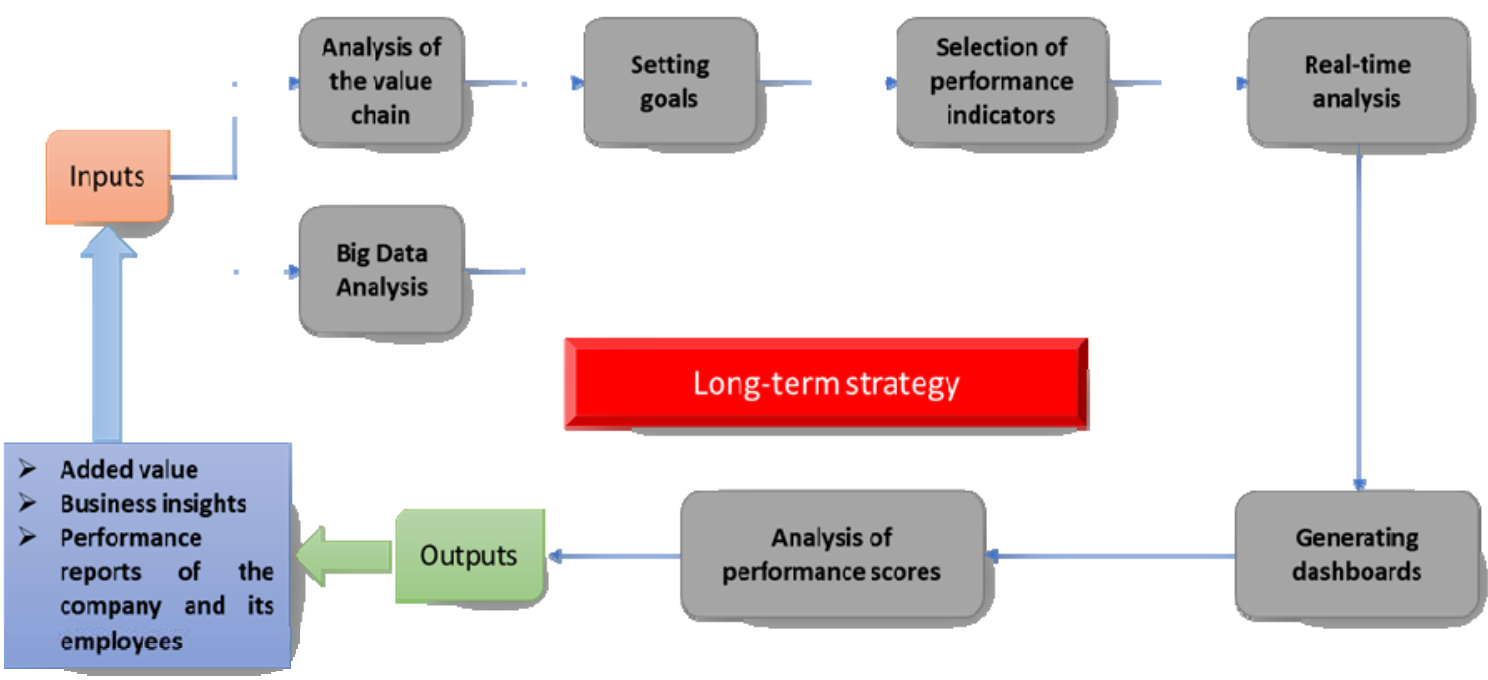

Figure 1: Performance management system - conceptual model 
Within the model, the long-term strategy is central, then based on the results of the value chain and "big-data" analysis the goals can be set based on the particularities of the company, after setting goals, to measure the progress towards achieving those goals, performance indicators have to be selected.

After the set of indicators is established the progress can be traced by using realtime analysis. The dashboards are useful tools to present the results to various stakeholders which might not have a financial background but are presented in a comprehensible manner. At the end of the fiscal year using a model to calculate a performance score based on the results provided by the set of indicators the company can calculate it's score and also compare it with its peers.

The support elements within the model have a very important role in creating value and achieving performance by the company, and these elements have the following features:

a) Analysis of the value chain - to understand how some business models work, it's important to know where, within the value chain, the company gets the most profits. Although a company could offer a large number of products and services, a business element could contribute to most profits. For example in the Healthcare \& Household Products sector companies such as Pfizer, Johnson \& Johnson, Novartis, AstraZeneca, Bayer, Merck, Sanofi, earn a significant portion of profits by capitalising on intangible assets in the form of patents in exchange for considerable sums of money. This element of the value chain of these companies is the result of investment in $R \& D$. To identify how a firm creates value based on its business model, it is possible to use the analysis of the value chain proposed by Michael Porter or the techniques of value analysis by Lawrence Miles;

b) "Big Data" analysis - managing "big data" results in better business knowledge, and this helps to improve decision-making and improves performance. Today the leaders in the digital era such as Apple, Google, Facebook and Amazon have built an empire of data used to shape and control the digital world. The various APIs used are processing large volumes of data that can help a company to analyse for, eg. the productivity of its employees, customer preferences and buying habits, where to cut costs and how to increase profitability. With the widespread use of $\mathrm{Al}$ - Artificial Intelligence, computing power has grown significantly, allowing for the exploration of larger sets of possible results. The "Big Data" analysis for large corporations is easier to achieve due to access to information on various platforms or services provided by companies that collect and process "big data". Such platforms are Yahoo Finance, Google Finance, Bloomberg Terminal, Thomson Reuters, S \& $P$, etc. However, access to a large amount of data allows with software such as SPSS, Excel, RapidMiner, etc. analysing data and formulating assumptions about how these companies create value and which indicators (financial and/or non-financial) lead to performance;

c) Setting goals - The corporate strategic objective is to increase the total corporate value to be higher than the sum of individual business units. A company's goals must first of all focus on a long-term perspective, then be flexible (can be adapted in the context of important internal or external events to the firm); accepted by 
stakeholders; measurable through a set of indicators, motivating, appropriate, understandable and achievable. A few key concepts by which objectives can be formulated with a long-term perspective and embraces the above features are "shared value" and "sustainable development". Large corporations, but not only, are using these concepts as guidelines to set their goals;

d) Selection of performance indicators - After the first steps were made, analyzing the value chain, "big data" analysis, and setting goals, it is necessary for a company to establish those indicators that measure the value created and performance results, taking into account the particularities of its business model. Based on the fact that performance is given by some elements at a company level, performance indicators are selected to cover all sources that contribute less or better to global performance; please see figure 2. To measure the overall performance of a company, we were considering selecting indicators based on the following criteria, indicators that measure: company value, sustainability, solvency, liquidity, profitability, indebtedness, operational performance, and global performance. The effect on the overall performance of selected indicators can be seen in asset growth rates, net profit, revenue, added value and sustainability.

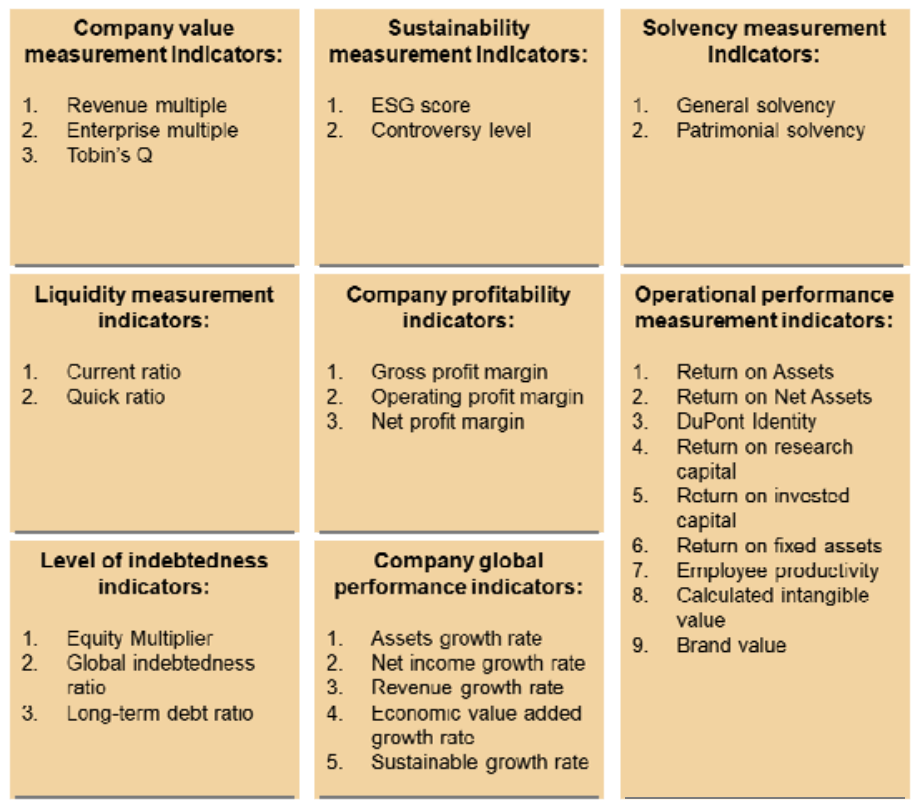

Figure 2: Performance indicators

e) Real-time analysis - Once the performance indicators have been selected, either static analysis can be based on annual, semestrial or quarterly results from financial reports, or by using software packages that can collect, process, and analyse real-time performance indicators in real time. Considering that this component of the performance management system involves a substantial investment from the company, it can be outsourced, with specialised companies on the real-time data analysis being present on the market; 
f) Generating dashboards - Dashboards are visual information management tools through graphs, which analyse and display performance indicators and key data to monitor a company's situation. They are customizable to meet the specific needs of a company. Behind such a dashboard is a database that is then displayed in the form of tables, charts, etc. Such an instrument is the most effective way to track multiple data sources because it provides a central location for companies to monitor and analyse performance. The best dashboards are the ones that focus on the most important aspects of the company. Unlike advanced business intelligence tools, dashboards are designed for quick analysis and informational awareness, especially for those stakeholders who do not have a financial education but can form an image of the company's state of affairs, such an example is shown in figure 3 .

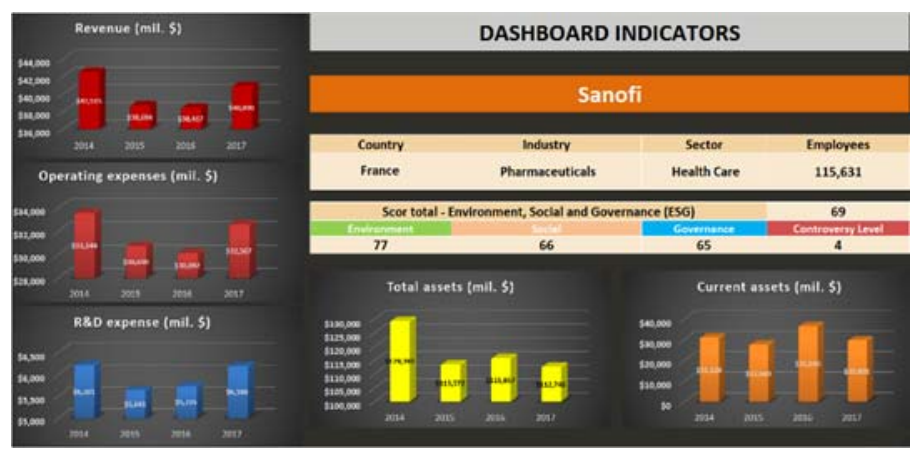

Figure 3: Dashbord performance indicators - Sanofi

g) Analysis of performance scores - By going through the previous stages of the performance management system and applying, on the one hand, the performance score model by normalizing (standardizing) the indicators, and on the other hand applying the $Z$ score function, we can analyze the scores at the company level, industry or sector level by comparing with the competitors. An important component of this stage is the impact analysis of the stakeholders.

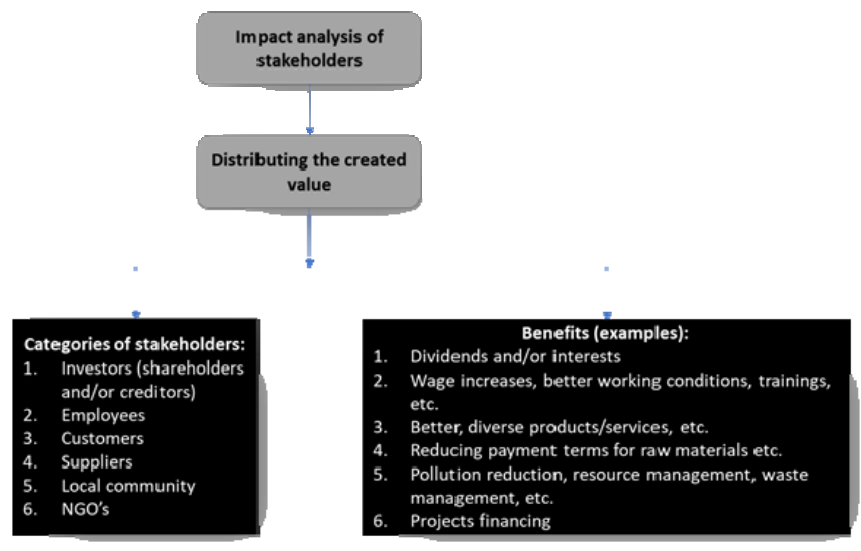

Figure 4: Stakeholders impact analysis and value distribution 
The results obtained by the company are analysed. Such an analysis allows the company to identify those critical stakeholders for its survival and to ensure that the satisfaction of their needs is of paramount importance. Most companies that have gone through this process quickly conclude that the needs of the three stakeholder groups (clients, employees and shareholders) must be met above all if a company wants to survive, be competitive and prosper. As a matter of fact, few companies have the resources to manage the needs, interests, goals of all stakeholders. Also at this stage, the dashboards can be used as a tool for presenting information on the performance scores obtained by the company, please see figure 5 .

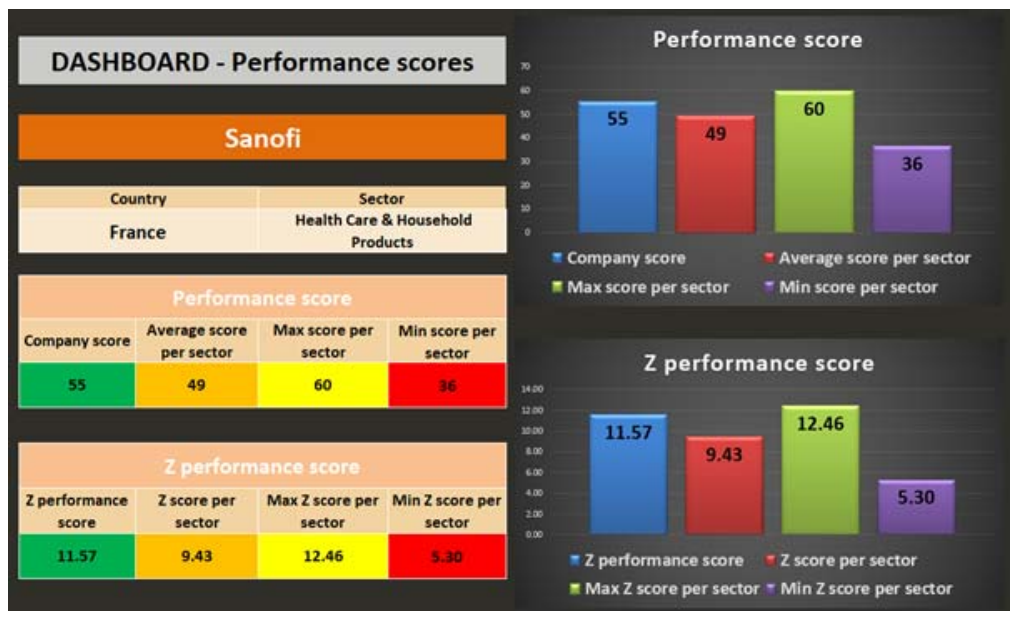

Figure 5: Dashbord performance scores - Sanofi

As a result of the steps in the company's overall performance management system, we achieve results or outputs in the form of a performance level (achieved or exceeded), business insight, added value etc. Successful implementation of the model for a company involves firstly establishing a long-term strategy and a systemic approach, these being the premises from which it starts. Then, the pattern having a cyclical character, after completing a cycle, at the beginning of the next cycle, the "inputs" category adds the "outputs" or the results of the previous cycle that help improve continuously.

\section{Performance management system in the technology sector}

Companies from the tech sector had strong growth in 2017 and 2018, due to the global spendings in purchasing software and tech services but also hardware and communication equipment. The performance of the tech sector was due to the robust growth of US, China, India, Indonesia, South Korea and the from the emerging countries like Brazil and Russia which resulted into a global tech market increase, but also the increased spending from the so-called "business technology", around 28\% (Bartels, 2017) in CRM, e-commerce, business analytics and other tech services. 
US companies dominate the tech sector with Apple and Amazon, the companies that in 2018, hit a market capitalisation of 1 trillion \$ each, which together with Facebook, Netflix and Google have a market capitalisation of about 3 trillion \$, approximately $10 \%$ of the value of the S\&P 500. After US tech companies, China, South Korea and Taiwan complete the top 10 tech sector with companies like Samsung (South Korea), Hon Hai Precision (Taiwan) and Tencent (China).

By analysing the value chain in the tech sector, the most value is created by the groundbreaking products and services in terms of software, hardware and other tech products. Also in the past decade for the tech sector, the value came also from goodwill, which is similar to intangible assets, it is shown on the balance sheet of the company, and it is recorded when a merger or an acquisition happens. Goodwill is considered a "premium fee" because it shows up only when "the purchase price is higher than the sum of the fair value of all identifiable tangible and intangible assets purchased in the acquisition and the liabilities assumed in the process (Hargrave, 2019)."

Even though goodwill has some similarities with intangible assets, there are important differences, such as various accounting approaches in estimating the value of goodwill, and most of the times the components of goodwill are subjectively valued.

Goodwill is an important factor in the value chain for the tech sector due to the increased of acquisitions, both in number and value. When Google (Alphabet) acquired YouTube in 2006 for 1,65 bn. $\$$ it was a huge deal, but ten years later, the amount increased significantly, with Microsoft acquiring Linkedln for 26,2 bn. \$ (2016), IBM acquiring Red Hat for 34 bn. \$ or the Dell acquiring EMC for 67 bn. \$, making this the largest deal in the tech sector so far.

For the tech companies ranked by profit from the Global Fortune 500 in 2017, the value of goodwill for 32 companies, please see figure 6 , counted for almost $300 \mathrm{bn}$. $\$$.

The companies selected to apply the steps from the performance management system - conceptual model, are the most profitable companies from the tech sector, based on the ranking provided by the Global Fortune 500 Magazine, in 2017. These companies had in 2017 a value (enterprise value) of over 7 trillion dollars, a net income of 245 billion dollars and over 1 million employees worldwide, as shown in tables 1 and 2.

Table 1: Tech companies, industry-based

\begin{tabular}{lccc}
\hline \multicolumn{1}{c}{ Industry } & No. of companies & $\begin{array}{c}\text { Net income } \\
\text { (mil. \$) }\end{array}$ & $\begin{array}{c}\text { Avg. no. of } \\
\text { employees }\end{array}$ \\
\hline Computer Software & 3 & 29.567 & 108.995 \\
Computer, Office Equipment & 6 & 54.178 & 157.631 \\
$\begin{array}{l}\text { Electronics, Electrical Equipment } \\
\text { Information Technology Services }\end{array}$ & 6 & 51.493 & 313.338 \\
$\begin{array}{l}\text { Internet Services and Retailing } \\
\text { Network and other Communication }\end{array}$ & 5 & 13.058 & 253.208 \\
$\begin{array}{l}\text { Equipment } \\
\text { Semiconductors and other Electronic }\end{array}$ & 5 & 51.699 & 85.787 \\
$\begin{array}{l}\text { Components } \\
\text { TOTAL }\end{array}$ & 5 & 12.075 & 52.417 \\
\hline
\end{tabular}


Based on the data from table 1, the most profitable industries from the tech sectors were Computer, Office Equipment (54 bn. \$) followed by Internet Services and Retailing (51,7 bn. \$) and Electronics, Electrical Equipment (51,5 bn. \$). Also, the Electronics, Electrical Equipment has the highest no. of employees.

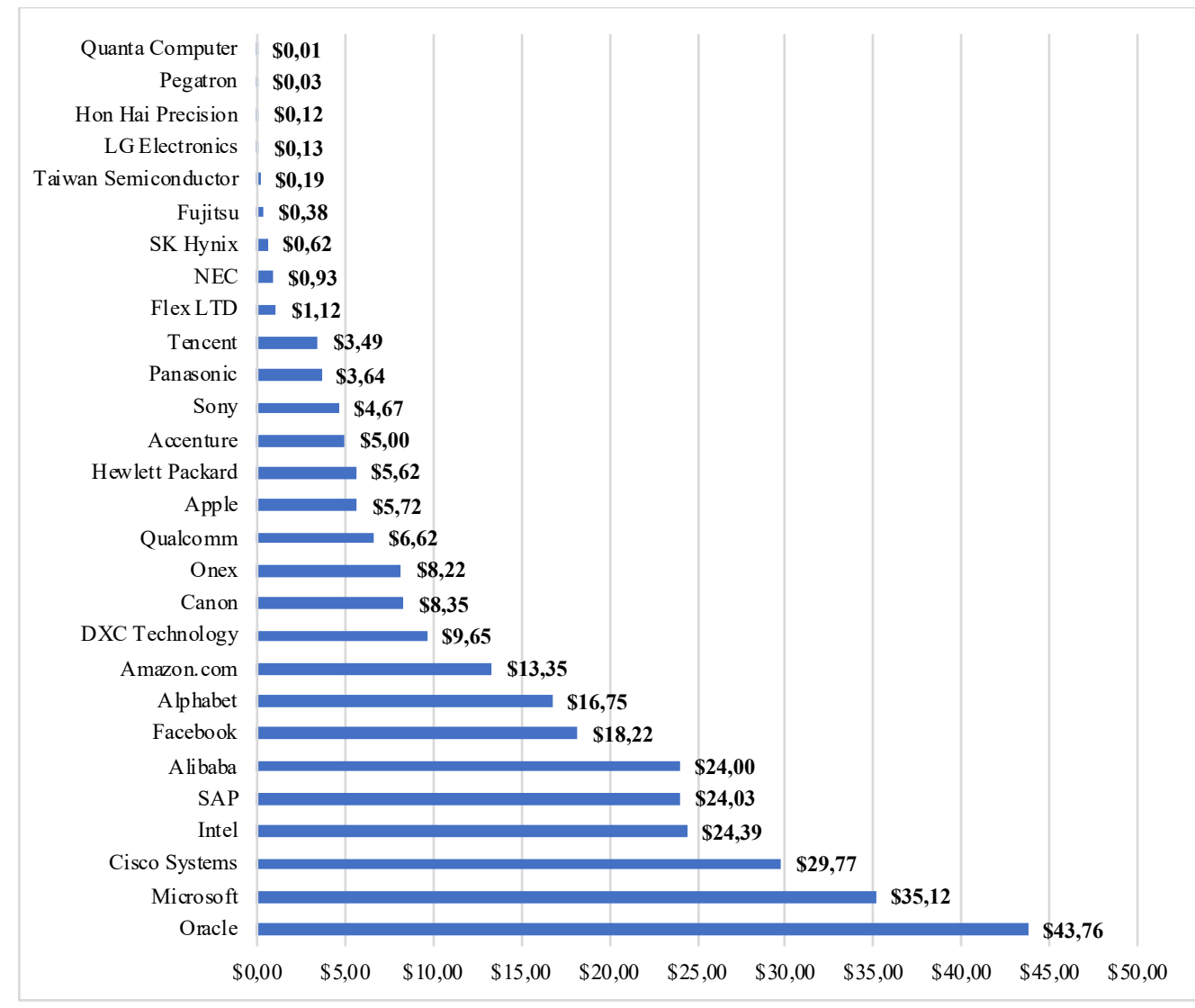

Figure 6: Goodwill value (bn. \$)

The figure above shows that goodwill in an important factor in the tech sector, and for the companies selected (32) the value of goodwill (294 bn. \$) is around $10 \%$ of the value of the total assets, which count for about 2,9 trillion $\$$.

Table 2: Top most profitable tech companies

\begin{tabular}{lccc}
\hline \multicolumn{1}{c}{ Company } & Industry & Country & $\begin{array}{c}\text { Enterprise } \\
\text { Value (bn. } \\
\text { (b) }\end{array}$ \\
\hline Apple & Computer, Office Equipment & Unites States & $\$ 1.120$ \\
Amazon.com & Internet Services and Retailing & Unites States & $\$ 974$ \\
Microsoft & Computer Software & Unites States & $\$ 784$ \\
Alphabet & Internet Services and Retailing & Unites States & $\$ 712$ \\
Alibaba & Internet Services and Retailing & China & $\$ 456$ \\
\hline \multicolumn{2}{|c|}{$\mathbf{2 3 9}-$} & & \\
\hline
\end{tabular}


Studies in Business and Economics no. 14(1)/2019

\begin{tabular}{|c|c|c|c|}
\hline Facebook & Internet Services and Retailing & Unites States & $\$ 429$ \\
\hline Tencent & Internet Services and Retailing & China & $\$ 415$ \\
\hline Samsung & Electronics, Electrical Equipment & South Korea & $\$ 263$ \\
\hline Intel & Semiconductors and other Electronic Components & Unites States & $\$ 230$ \\
\hline $\begin{array}{l}\text { Taiwan } \\
\text { Semiconductor }\end{array}$ & Semiconductors and other Electronic Components & Taiwan & $\$ 205$ \\
\hline Cisco Systems & Network and other Comm. Equip. & Unites States & $\$ 200$ \\
\hline Pegatron & Computer, Office Equipment & Taiwan & $\$ 191$ \\
\hline $\begin{array}{l}\text { Quanta } \\
\text { Computer }\end{array}$ & Computer, Office Equipment & Taiwan & $\$ 187$ \\
\hline Oracle & Computer Software & Unites States & $\$ 184$ \\
\hline IBM & Information Technology Services & Unites States & $\$ 167$ \\
\hline SAP & Computer Software & Germany & $\$ 148$ \\
\hline $\begin{array}{l}\text { Compal } \\
\text { Electronics }\end{array}$ & Computer, Office Equipment & Taiwan & $\$ 115$ \\
\hline Accenture & Information Technology Services & Ireland & $\$ 105$ \\
\hline Qualcomm & Network and other Comm. Equip. & Unites States & $\$ 90$ \\
\hline Sony & Electronics, Electrical Equipment & Japan & $\$ 69$ \\
\hline SK Hynix & Semiconductors and Other Electronic Components & South Korea & $\$ 59$ \\
\hline $\begin{array}{l}\text { Hon Hai } \\
\text { Precision }\end{array}$ & Electronics, Electrical Equipment & Taiwan & $\$ 45$ \\
\hline Canon & Computer, Office Equipment & Japan & $\$ 35$ \\
\hline Onex & Semiconductors and other Electronic Components & Canada & $\$ 32$ \\
\hline $\begin{array}{l}\text { Hewlett } \\
\text { Packard }\end{array}$ & Computer, Office Equipment & Unites States & $\$ 32$ \\
\hline $\begin{array}{l}\text { DXC } \\
\text { Technology }\end{array}$ & Information Technology Services & Unites States & $\$ 30$ \\
\hline Panasonic & Electronics, Electrical Equipment & Japan & $\$ 30$ \\
\hline LG Electronics & Electronics, Electrical Equipment & South Korea & $\$ 21$ \\
\hline Fujitsu & Information Technology Services & Japan & $\$ 17$ \\
\hline LG Display & Electronics, Electrical Equipment & South Korea & $\$ 11$ \\
\hline Flex $L T D$ & Semiconductors and other Electronic Components & Singapore & $\$ 9$ \\
\hline NEC & Information Technology Services & Japan & $\$ 9$ \\
\hline TOTAL & & & $\$ 7.372$ \\
\hline
\end{tabular}

The top is dominated by the US companies (12), followed by Japan (5), Taiwan (5) and South Korea (4), China (2), Germany, Ireland, Singapore and Canada with one company each country.

In the tech sector, the goals set to improve the overall performance identified by the their leaders are: to refine the internal systems; to continue the research on industry and customers; increase the use of blockchain applications; to educate the customers about new tech; reduce operational costs; increase the delivery of value to customers; to be prepared for tech sector upcoming changes; to improve the actual products and services; to expand to larger markets, suggests Forbes Technology Council (2018). 
In order to measure the global performance of the tech sector, and calculate the performance score we have selected the following performance indicators: ESG score and Controversy level from Yahoo Finance, provided by Sustainalytics; Tobin's ratio; Enterprise multiple; General solvency; Quick ratio; Net profit margin; Goodwill+Intangible assets to total assets ratio; Financial leverage and the DuPont Identity. The financial data for the 32 companies were collected from Yahoo Finance and the financial statements.

After we computed the data collected and calculated the indicators, we normalised (standardised) the variables using the formula below, and the scores calculated by sectors are shown in table 3.

$X_{i j n o r m}=90 * \frac{x d]-x i m ! n}{x I m a x-x I m \mid n}+10$

Generic performance score $=\Sigma \frac{\text { xilnorm }}{n}+10$

Where:

$x_{i j}-$ is the result of variable $i$ for company $j$

$x_{i m i n}-$ represents the minimum level of variable $i$

$x_{i m a x}$ - represents the maximum level of variable $i$

The normalization (standardization) interval is [10; 100]

Table 3: Performance scores of the sample companies in the tech sector

\begin{tabular}{|c|c|c|c|c|c|c|c|c|c|c|c|}
\hline Company & A & B & C & D & $\mathbf{E}$ & $\mathbf{F}$ & G & $\mathbf{H}$ & 1 & $\mathbf{J}$ & $\begin{array}{c}\text { Performance } \\
\text { score }\end{array}$ \\
\hline Facebook & 22 & 100 & 32 & 36 & 100 & 47 & 100 & 47 & 50 & 65 & 60 \\
\hline Samsung & 68 & 100 & 25 & 11 & 41 & 100 & 50 & 18 & 51 & 64 & 53 \\
\hline$S A P$ & 79 & 55 & 30 & 46 & 29 & 15 & 48 & 100 & 52 & 62 & 52 \\
\hline Qualcomm & 68 & 100 & 28 & 31 & 22 & 66 & 34 & 35 & 54 & 57 & 49 \\
\hline Microsoft & 72 & 78 & 41 & 40 & 16 & 10 & 64 & 39 & 58 & 69 & 49 \\
\hline Alibaba & 15 & 55 & 36 & 76 & 30 & 35 & 68 & 54 & 52 & 63 & 48 \\
\hline Intel & 100 & 78 & 27 & 21 & 27 & 11 & 44 & 57 & 52 & 60 & 48 \\
\hline $\begin{array}{l}\text { Taiwan } \\
\text { Semiconductor }\end{array}$ & 91 & 33 & 30 & 24 & 48 & 34 & 91 & 11 & 51 & 66 & 48 \\
\hline Amazon.com & 10 & 78 & 79 & 100 & 14 & 14 & 12 & 30 & 63 & 59 & 46 \\
\hline Apple & 61 & 100 & 35 & 34 & 18 & 11 & 58 & 13 & 56 & 73 & 46 \\
\hline Cisco Systems & 86 & 55 & 27 & 32 & 24 & 16 & 55 & 49 & 53 & 61 & 46 \\
\hline Alphabet & 47 & 100 & 31 & 42 & 53 & 16 & 35 & 25 & 50 & 57 & 46 \\
\hline IBM & 77 & 55 & 35 & 25 & 13 & 14 & 25 & 61 & 72 & 71 & 45 \\
\hline SK Hynix & 68 & 55 & 25 & 10 & 47 & 14 & 91 & 15 & 51 & 71 & 45 \\
\hline Tencent & 15 & 55 & 40 & 56 & 23 & 21 & 79 & 23 & 53 & 69 & 43 \\
\hline Oracle & 61 & 55 & 29 & 28 & 17 & 28 & 31 & 68 & 57 & 57 & 43 \\
\hline
\end{tabular}


Studies in Business and Economics no. 14(1)/2019

\begin{tabular}{llllllllllll}
\hline Accenture & 75 & 33 & 41 & 38 & 20 & 15 & 32 & 45 & 54 & 74 & 43 \\
Onex & 19 & 10 & 27 & 34 & 13 & 17 & 31 & 67 & 100 & 100 & 42 \\
DXC & 52 & 55 & 25 & 16 & 20 & 13 & 25 & 89 & 55 & 60 & 41 \\
Technology & & & & & & & & & & & \\
Canon & 68 & 55 & 24 & 17 & 29 & 20 & 22 & 51 & 52 & 57 & 40 \\
Pegatron & 61 & 55 & 82 & 19 & 18 & 15 & 11 & 10 & 57 & 58 & 39 \\
Sony & 70 & 55 & 27 & 19 & 14 & 13 & 22 & 19 & 68 & 62 & 37 \\
Panasonic & 52 & 78 & 25 & 15 & 16 & 14 & 15 & 28 & 59 & 60 & 36 \\
NEC & 82 & 55 & 23 & 17 & 18 & 14 & 12 & 24 & 57 & 55 & 36 \\
Fujitsu & 77 & 55 & 25 & 14 & 19 & 14 & 18 & 19 & 56 & 61 & 36 \\
Hon & 56 & 78 & 24 & 22 & 18 & 14 & 15 & 10 & 57 & 60 & 35 \\
Precision & & & & & & & & & & & 35 \\
Quanta & 47 & 10 & 100 & 23 & 15 & 15 & 12 & 10 & 63 & 59 & 34 \\
Computer & & & & & & & & & & & 34 \\
LG Display & 58 & 55 & 23 & 12 & 24 & 13 & 24 & 15 & 53 & 60 & 33 \\
Flex LTD & 65 & 33 & 26 & 22 & 15 & 12 & 12 & 28 & 62 & 61 & 33 \\
LG Electronics & 65 & 55 & 24 & 14 & 18 & 11 & 15 & 16 & 56 & 59 & 28 \\
Compal & 24 & 55 & 64 & 20 & 16 & 13 & 10 & 10 & 59 & 56 & \\
Electronics & & & & & & & & & & & \\
HP & 86 & 55 & 10 & 26 & 10 & 14 & 20 & 37 & 10 & 10 & \\
\hline
\end{tabular}

Note A - ESG Score; B - Controversy level; C - Tobin's ratio; D - Enterprise multiple; E - General solvency; F Quick ratio; G - Net profit margin; $\mathbf{H}$ - Goodwill+Intangible assets to total assets ratio; I - Financial leverage; J DuPont Identity.

Based on the calculated performance score, Facebook (US) has the highest score (60), followed by Samsung - South Korea (53) and SAP - Germany (52). The minimum score is 28 - HP (US), the maximum score is 60 - Facebook (US) while the average score for the selected 32 companies is 42 .

In figure 7 based on the performance scores calculated and the data collected, a dashboard sample is presented with main information about the company. Several users can use it, shareholders, analysts, etc. people without a financial background. The results presented in the dashboard aim to briefly present the current situation of the company and compared with its peers. Due to the fact that the performance management system is used over a long period, and the outputs of this year become inputs for the next year circle, it accumulates data, and it can show the evolution of various key indicators of the company.

In the example from figure 7 , Accenture has a performance score just above the average of the tech sector. The information shown is the country (Ireland), industry (Information technology services), sector (Technology), employees (449.000), ESG score (75, maximum 100), Controversy level (1, maximum 5) and performance score (43). 


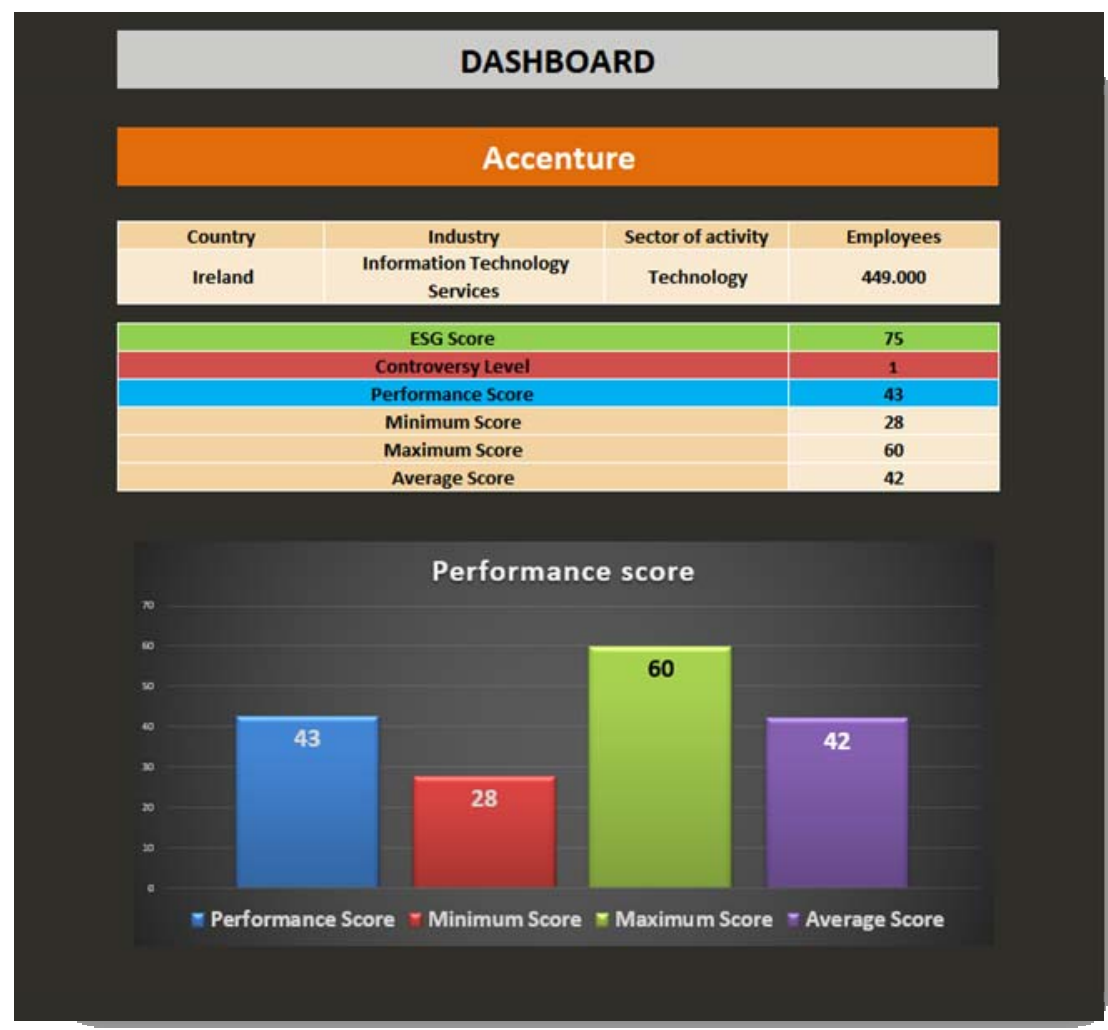

Figure 7: Dashboard - Accenture

\section{Conclusion}

Focusing only on maximising the value of the company or shareholder wealth as the primary objective, highlighted by voices like Milton Friedman (1970), pushed managers towards a short-term oriented approach that caused damage to the long-term perspective of the companies. Today we have to take into consideration the needs of various parties (stakeholders) that bring value to the company and include them into the management system. Furthermore, concepts like "shared value" and "sustainability" led in the first phase to a change of perspective in the field, but then but has highlighted an already existing problem, namely how we measure and manage it?

Although companies are currently pursuing and reporting countless financial, social, and environmental indicators, in part through the social sector's efforts to develop more sophisticated social impact assessment methods, there is also the need for integrated reporting aimed at adding sustainability measures to financial statements.

Based on the conceptual performance management system model, we are trying to integrate the main concerns mentioned above: pursue a long-term strategy, the model is a cyclical one, can and will be used year after year improving by the outputs that will become valuable inputs; takes into consideration the stakeholders not only the 
shareholders, then it provides a set of indicators that covers both financial and nonfinancial indicators, by including important topics like "sustainability".

By applying the performance management system - conceptual model on a sector of activity gives the possibility to identify the main value creators, analyze and select from huge amounts of data, set goals, select the proper indicators, create an interactive dashboard, analyze it with various stakeholders, share the performance results and the value created, and use in the end use all the outputs as inputs for the next cycle.

\section{References}

Armstrong, M. (2009). Armstrong's Handbook of performance management: an evidence-based guide to delivering high performance. Kogan Page Publishers.

Bartels, A. Global Tech Market Will Grow By 4\% In 2018, Reaching \$3 Trillion. Forrester. [online] Available: https://www.forbes.com/sites/forrester/2017/10/18/global-tech-market-will-growby-4-in-2018-reaching-3-trillion/\#255243f12c9e, [Acceses 22.04.2019].

Bourne, M., \& Bourne, P. (2012). Handbook of corporate performance management. John Wiley \& Sons.

Davis, S., \& Albright, T. (2004). An investigation of the effect of balanced scorecard implementation on financial performance. Management accounting research, 15(2), 135-153.

Deloitte. (2013). Integrated performance management for sustained growth. Deloitte Australia.

Ferreira, A., \& Otley, D. (2009). The design and use of performance management systems: An extended framework for analysis. Management accounting research, 20(4), 263-282.

Forbes Technology Council (2018). 14 Tech Leaders Share Their 2018 Goals To Improve Their Companies. [online] Available: https://www.forbes.com/sites/forbestechcouncil/2018/02/09/14-tech-leaders-share-their2018-goals-to-improve-their-companies/\#48ea682d65a7 [Accesed 22.04.2019].

Franco-Santos, M., \& Bourne, M. (2005). An examination of the literature relating to issues affecting how companies manage through measures. Production Planning \& Control, 16(2), 114-124.

Hargrave, M. (2019). Goodwill Definition. Investopedia. [online] Available: https://www.investopedia.com/terms/g/goodwill.asp [Accesed 22.04.2019].

Kaplan, R. and Norton, D. (1992) The Balanced Scorecard-Measures That Drive Performance. Harvard Business Review, 79.

Kramer, M. R., \& Porter, M. (2011). Creating shared value. Harvard business review, 89(1/2), 62-77.

Lee, C. D. (2005). Rethinking the goals of your performance-management system. Employment Relations Today, 32(3), 53-60.

Lohman, C., Fortuin, L., \& Wouters, M. (2004). Designing a performance measurement system: A case study. European Journal of Operational Research, 156(2), 267-286.

Magretta, J., \& Stone, N. (2002). What management is. Simon and Schuster.

Melnyk, S. A., Bititci, U., Platts, K., Tobias, J., \& Andersen, B. (2014). Is performance measurement and management fit for the future?. Management Accounting Research, 25(2), 173-186.

Neely, A., Mills, J., Platts, K., Richards, H., Gregory, M., Bourne, M., \& Kennerley, M. (2000). Performance measurement system design: developing and testing a process-based approach. International Journal of Operations \& Production Management, 20(10), 11191145.

Olsen, E. O., Zhou, H., Lee, D. M., Ng, Y. E., Chewn Chong, C., \& Padunchwit, P. (2007). Performance measurement system and relationships with performance results: A case analysis of a continuous improvement approach to PMS design. International Journal of Productivity and Performance Management, 56(7), 559-582. 